Western Washington University Western CEDAR

\title{
Ignoring History, Denying Racism: Mounting Evidence for the Marley Hypothesis and Epistemologies of Ignorance
}

\author{
Courtney M. Bonam \\ University of Illinois at Chicago \\ Vinoadharen Nair Das \\ University of Illinois at Chicago \\ Brett R. Coleman Western Washington University \\ Phia Salter \\ Texas A\&M University
}

Follow this and additional works at: https://cedar.wwu.edu/woodring_dei

Part of the Education Commons

\section{Recommended Citation}

Bonam, C. M., Nair Das, V., Coleman, B. R., \& Salter, P. (2019). Ignoring History, Denying Racism: Mounting Evidence for the Marley Hypothesis and Epistemologies of Ignorance. Social Psychological and Personality Science, 10(2), 257-265. https://doi.org/10.1177/1948550617751583

This Article is brought to you for free and open access by the Woodring College of Education at Western CEDAR. It has been accepted for inclusion in Woodring Scholarship on Diversity, Equity, Inclusion by an authorized administrator of Western CEDAR. For more information, please contact westerncedar@wwu.edu. 


\title{
Ignoring History, Denying Racism: Mounting Evidence for the Marley Hypothesis and Epistemologies of Ignorance
}

\author{
Courtney M. Bonam ${ }^{1,2}$, Vinoadharen Nair Das², Brett R. Coleman², \\ and Phia Salter ${ }^{4}$
}

\begin{abstract}
In demonstration of the Marley hypothesis, Nelson, Adams, and Salter showed that differences in critical historical knowledge (i.e., knowledge of past racism) and motivation to protect group esteem predicted present-day racism perceptions among Whites and Blacks attending different, racially homogenous universities. The present Study I conceptually replicates these findings among Whites and Blacks attending the same racially diverse university. Consistent with previous findings, Whites (vs. Blacks) displayed less critical historical knowledge, explaining their greater denial of systemic racism. Moreover, stronger racial identity among Whites predicted greater systemic racism denial. A brief Study 2 intervention boosts Whites' racism perceptions. People who learned the critical history of U.S. housing policy (vs. a control group) acknowledged more systemic racism. The present work interrupts seemingly normal and neutral dominant perspectives, provides mounting evidence for an epistemologies of ignorance framework, and suggests that learning critical history can help propel anti-racist understandings of the present.
\end{abstract}

\section{Keywords}

sociocultural factors, racial identity, racism, social perception, intergroup dynamics

Black versus White Americans report higher rates of racism and racial tensions (Pew Research Center, 2016). When Whites do acknowledge racism, they tend to define it as isolated incidents, rather than long-standing, systemic problems with policies, laws, and institutions (Sommers \& Norton, 2006). What can explain these perceptual discrepancies? Popular narratives focus on why Blacks see so much racism (Wise, 2006) - instead of why Whites see so little. Contrastingly, Nelson et al.'s (2013) examination of this discrepancy interrupts treatment of dominant group perspectives as neutral, accurate reflections of reality. They employ an epistemologies of ignorance framework to examine ignorance technologies: the "cultural-psychological tools ${ }^{1}$ that afford denial of and inaction about injustice" (Adams \& Markus, 2004; Mills, 1997; Nelson, Adams, \& Salter, 2013, p. 213; Sullivan \& Tuana, 2007). They find that these tools shape Whites' racism perceptions, by comparing White to Black Americans from different, racially homogenous contexts. The present work replicates these findings in a racially diverse context (Study 1) and develops an intervention boosting Whites' racism perceptions (Study 2).

\section{The Tools: Ignorance and Identity}

Nelson and colleagues argue that two tools-(1) lacking critical historical knowledge of past racism and (2) motivation to protect group esteem, in the form of positive racial identity - predict Whites' present-day racism denial. The Marley hypothesis tests this first tool, and it is a nod to Bob Marley's lyric asserting the importance of knowing your history to "know where you're comin from" (Marley \& Williams, 1983). Consistent with Marley's insight and work linking historical knowledge with perceptions of the present (Liu \& Hilton, 2010), Nelson and colleagues theorize that Whites' lacking critical historical knowledge contributes to presentday racism denial.

Nelson and colleagues also explore racial identity. Whites are generally motivated to maintain a positive group image (Unzueta \& Lowery, 2008), which includes adhering to social

\footnotetext{
'African American Studies Department, University of Illinois at Chicago, Chicago, IL, USA

${ }^{2}$ Department of Psychology, University of Illinois at Chicago, Chicago, IL, USA

${ }^{3}$ Health and Community Studies Department, Western Washington University, Bellingham, WA, USA

${ }^{4}$ Department of Psychology and Africana Studies Program, Texas A\&M University, College Station, TX, USA
} 
egalitarianism norms (Bergsieker, Shelton, \& Richeson, 2010). Because acknowledging racism threatens this image, Whites may deny racism to protect group esteem. This racial identity relevance hypothesis should be particularly applicable to systemic (vs. isolated) racism: Systemic racism examples implicate society writ large, whereas isolated examples implicate individuals. Sense of self-identity and group identity are more easily separated from isolated examples (Adams, Tormala, \& O'Brien, 2006).

Nelson and colleagues tested these hypotheses by comparing racism perceptions among White students at a Primarily White Institution (PWI), to Black students at two historically Black colleges or universities (HBCUs). White (vs. Black) participants perceived less systemic and isolated present-day racism. Supporting the Marley hypothesis, lower critical historical knowledge among Whites (vs. Blacks) mediated these perceptual gaps. Supporting the racial identity relevance hypothesis, stronger positive racial identity among White participants predicted greater denial of systemic (but not isolated) racism while Black participants showed the opposite pattern.

\section{The Present Work: Mounting Evidence for Epistemologies of Ignorance}

The present work strengthens and extends evidence for Nelson and colleagues' findings. We conduct a conceptual replication of Nelson and colleagues' study (Study 1). Their study likely maximized the possibility of capturing racial group differences by recruiting Black and White student samples differing not only in race but also in institutional-cultural context. HBCU institutional culture affirms critical historical knowledge as an important form of cultural engagement and racial socialization (Bynum, Burton, \& Best, 2007; Van Camp, Barden, Sloan, $\&$ Clarke, 2009), whereas PWIs arrest racial development (Cabrera, Watson, \& Franklin, 2016). One reinforces, whereas the other dismantles, ignorance technologies.

We conduct our conceptual replication under conditions that might, by contrast, minimize differences between Black and White participants. First, we hold institutional-cultural context constant across Black and White participants-everyone attends the same university. Second, this university is one of the nation's most racially diverse (Smith-Barrow, 2015), is a minority serving institution (MSI, Civil Rights Office, 2016), and has national awards for leadership on diversity issues in higher education.

This context likely minimizes Black-White racism perception gaps. Freshman and seniors attending this racially diverse university, versus peer institutions, report more interracial interactions (Institutional Research Office, 2015). Such intergroup contact boosts structural thinking among White college students, especially when embedded in curriculum addressing systemic inequality (Lopez, 2004; Lopez, Gurin, \& Nagda, 1998), which this university emphasizes (see Supplemental Material for details). This emphasis may help students acknowledge racism. Further, perhaps this context affirms White students' egalitarian identity, reducing motivation to protect group esteem by denying racism (Adams et al., 2006; Gunn \& Wilson, 2011).

Despite minimizing dynamics, we expect to replicate Nelson and colleagues' findings. The university is, but one institution shaping daily lives, embedded in a racially divided (Charles, 2003), color-blind nation (Bonilla-Silva, 2015). We also provide causal evidence for Nelson and colleagues' framework, by delivering a brief educational intervention boosting Whites' racism perceptions (Study 2).

\section{Study I \\ Ignoring History, Denying Racism}

Study 1 reexamines the Black-White racism perception gap at a racially diverse university. We expect White (vs. Black) students will have less knowledge of critical historical facts, which will explain why they deny systemic and isolated racism. Additionally, racial identity relevance will predict greater denial of systemic (but not isolated) racism for White students. Evidence supporting these predictions would conceptually replicate and extend Nelson and colleagues' findings to a racially diverse context.

\section{Method}

\section{Participants and Setting}

Prior to beginning data collection and given feasibility issues related to recruiting from a minority population, we decided to recruit as many participants as possible over two semesters. The study took place at a large racially diverse metropolitan university in the U.S. Midwest, whose undergraduate population is approximately $36 \%$ White, $26 \%$ Hispanic/Latino, $23 \%$ Asian, $8 \%$ Black, and 7\% some Other racial/ethnic group. In contrast, the PWI in Nelson and colleagues' study was $72 \%$ White and 5\% Black. Both HBCUs from Nelson and colleagues' study were over $90 \%$ Black and less than $5 \%$ White.

Initially, 111 White and 43 Black ( 88 women, 66 men, $M_{\text {age }}$ $\left.=19.4, S D=1.7, M d n_{\text {age }}=19.0\right)$ students took part in a laboratory study for course credit. ${ }^{2}$ One White participant did not complete the racial identity relevance measure and was excluded from analyses involving this measure.

\section{Procedure and Measures}

After providing informed consent, participants completed three measures in groups of - one to six people in a small computer laboratory on campus. Participants completed the same measures of critical historical knowledge, racial identity relevance, and perception of racism reported in Nelson and colleagues (2013; see Supplement for all verbatim items.) $)^{3}$

\section{Historical Knowledge}

Participants responded true or false to 11 true statements and 5 false statements about past racism and indicated their level of certainty on a scale from 1 (guessing) to 5 (certain). Example 
true statement: "The Federal Bureau of Investigation (FBI) has employed illegal techniques (e.g., hidden microphones in motels) in an attempt to discredit African American political leaders during the civil rights movement." Example false statement: "African American Paul Ferguson was shot outside of his Alabama home for trying to integrate professional football."

\section{Racial Identity Relevance}

Participants indicated the extent to which they agreed or disagreed, from 1 (strongly disagree) to 7 (strongly agree), with the 4 items $(\alpha=.73)$ of the Private Regard subscale of the Collective Self-Esteem Scale (Luhtanen \& Crocker, 1992). Items were adapted to reference racial identity (e.g., In general, I'm glad to be a member of my racial group).

\section{Perceptions of Racism}

Across 14 items on a scale from 1 (not at all) to 7 (certainly), participants indicated the extent to which they perceived racism in nine cases describing systemic manifestations (e.g., the portrayal of African Americans in U.S. entertainment media; $\alpha=.83$ ) and five cases describing isolated incidents (e.g., Several people walk into a restaurant at the same time. The server attends to all the White customers first. The last customer served happens to be the only person of color; $\alpha=.65$ ).

\section{Results}

We first examined racial differences in racism perceptions by conducting a mixed-model analysis of variance (ANOVA) with participant race (White, Black) as between-subjects factor and racism type (isolated, systemic) as within-subjects factor. Consistent with predictions, an interaction emerged, $F(1,152)=$ $7.18, p=.008, \eta_{\mathrm{p}}^{2}=.05$. White Americans perceived less racism than Black Americans for systemic manifestations, $F(1,152)=11.58, p<.001, \eta_{\mathrm{p}}^{2}=.07$, but White and Black Americans' perceptions of racism did not differ for isolated incidents, $F(1,152)>1$. Both groups also perceived more isolated than systemic racism, but this gap was larger for White Americans, $F(1,152)=72.14, p<.001, \eta_{\mathrm{p}}^{2}=.32$, than it was for Black Americans, $F(1,152)=4.54, p=.035, \eta_{\mathrm{p}}^{2}=.03$ (see Table 1).

Signal detection theory (see Nelson et al., 2013) guided our analytic approach for critical historical knowledge and supported the Marley hypothesis: Black participants tended to have higher hit rates but not higher false alarm rates than White participants. Namely, Black (vs. White) participants more often confidently responded true to consensually true items (hits) but not false items (false alarms). Critically, the index of sensitivity $\left(d^{\prime}\right)$, which Nelson and colleagues referred to as reality attunement, followed the same pattern: Black (vs. White) participants more often effectively discriminated between truthful signal and fictional noise, $d=.49$ (see Table 1). Note that, as in Nelson and colleagues' study, these analyses count uncertain
Table I. Between-Group Differences in Means for Key Study I Variables.

\begin{tabular}{|c|c|c|c|}
\hline Measure & $\begin{array}{c}\text { Black } \\
\text { Americans }\end{array}$ & $\begin{array}{l}\text { White } \\
\text { Americans }\end{array}$ & $t(d f)$ \\
\hline POR: isolated incidents & $4.91(1.09)$ & $4.79(1.17)$ & $0.58(152)$ \\
\hline POR: systemic manifestations & $4.54(1.14)$ & $3.88(1.07)$ & $3.40^{* * * *}(152)$ \\
\hline Historical knowledge: hit rate & $0.63(0.21)$ & $0.48(0.23)$ & $3.7 \mid * * *(152)$ \\
\hline $\begin{array}{l}\text { Historical knowledge: false } \\
\text { alarm rate }\end{array}$ & $0.15(0.14)$ & $0.11(0.12)$ & $1.43(152)$ \\
\hline $\begin{array}{l}\text { Historical knowledge: reality } \\
\text { attunement }\left(d^{\prime}\right)\end{array}$ & $1.61(0.62)$ & $1.27(0.75)$ & $2.66^{* *}(152)$ \\
\hline Identity relevance & $5.94(0.95)$ & $5.76(1.07)$ & $0.96(151)$ \\
\hline
\end{tabular}

Note. Standard deviations are in parentheses. POR $=$ perception of racism. $* * * p<.001 .{ }^{* *} p<.001$.

Table 2. Correlations ( $r$ ) Between Dependent Measures in Study I.

\begin{tabular}{lccc}
\hline Measure & 2 & 3 & 4 \\
\hline I. Historical knowledge: reality attunement $\left(d^{\prime}\right)$ & .08 & $.21^{*}$ & $-.16^{*}$ \\
2. POR: isolated incidents & & $.49 * * *$ & -.05 \\
3. POR: systemic manifestations & & & .12 \\
4. Identity relevance & & & \\
\hline
\end{tabular}

Note. POR $=$ perception of racism.

$* p<.05 . * * * p<.001$.

responses (i.e., responses with participant reported certainty ratings of less than 3) as false. Without this adjustment, conclusions regarding false alarm and hit patterns remain the same; the $d^{\prime}$ group difference also remains but is smaller, $t(152)=$ $1.76, p=.080, d=.33$ (see Table 2 for bivariate correlations between dependent variables).

\section{Testing the Marley Hypothesis and Role of Identity Relevance Simultaneously}

To test both the Marley hypothesis and the role of racial identity relevance as separable processes each helping to explain the Black-White gap in racism perceptions, we conducted mediated moderation regression analyses using Model 5 of the SPSS Process macro Version 2.15 (Hayes, 2013), with 10,000 bias-corrected bootstrap resamples. The analyses test two primary questions: (1) whether participant race has an indirect effect on perceptions of racism through the reality attunement $\left(d^{\prime}\right)$ measure of historical knowledge (controlling for racial identity relevance and its interaction with participant race) and (2) whether racial identity relevance moderates the direct effect (i.e., controlling for historical knowledge) of participant race on perceptions of racism. We conducted two separate sets of analyses, one with isolated and one with systemic racism perceptions as the primary dependent variable. A $95 \%$ confidence interval (CI) excluding zero indicates a significant indirect effect at the $p<.05$ level (see Table 2 for identity relevance means by participant race). Note that, again as in Nelson and colleagues' study, the following analyses count uncertain 


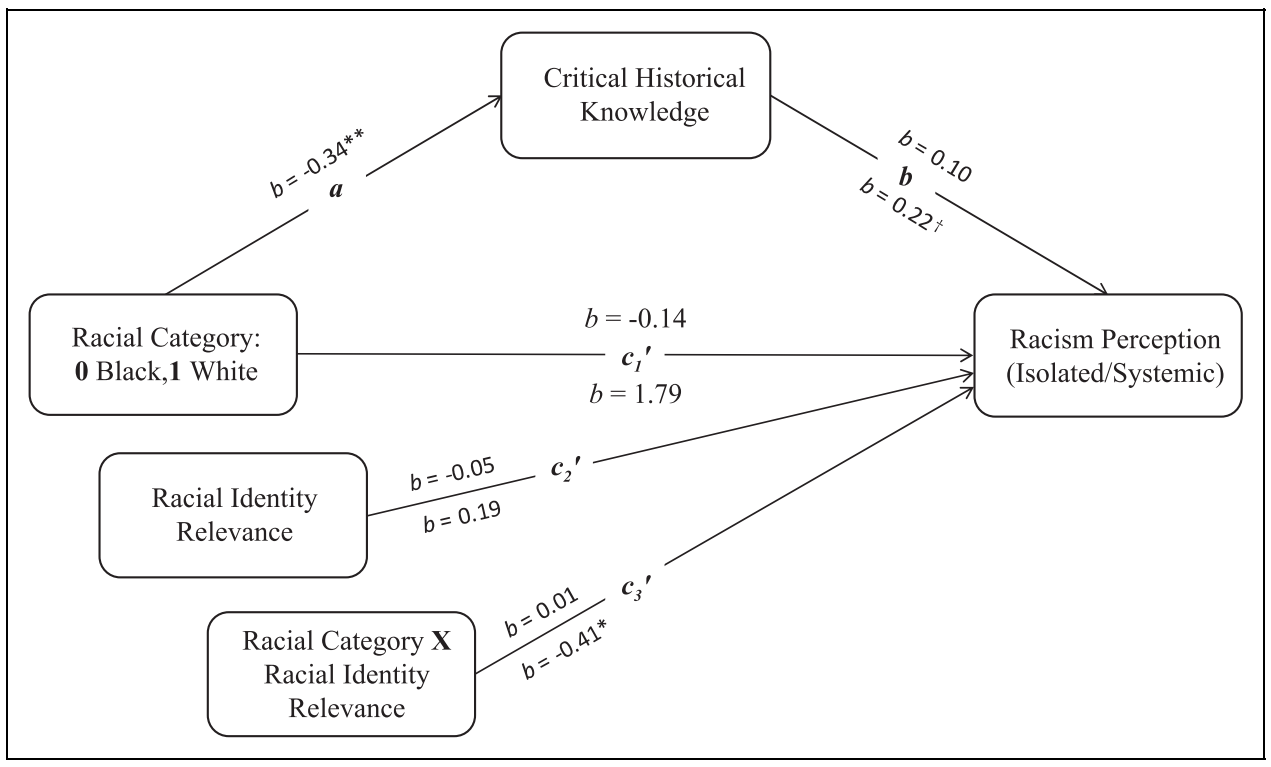

Figure I. A statistical depiction of Study I's model, simultaneously testing the Marley and identity relevance hypotheses. Unstandardized path estimates predicting isolated and systemic racism perceptions are above and below the lines, respectively. (Higher racial identity relevance indicates a more positive racial identity; reality attunement $\left(d^{\prime}\right)$ is the measure of critical historical knowledge here.). ${ }^{* *} p<.0 \mathrm{l}$. ${ }^{*} p<$ .05. ${ }^{\dagger} p<.1$.

responses as false. Without this adjustment, all conclusions remain the same.

Marley hypothesis. Unexpectedly, the participant race $\rightarrow$ historical knowledge $\rightarrow$ perceptions of isolated racism indirect path was nonsignificant, $b=-0.03, S E=0.05$, CI $[-0.175,0.055]$. As expected, the participant race $\rightarrow$ historical knowledge $\rightarrow$ perceptions of systemic racism indirect path was significant, $b=-0.08, S E=0.05$, CI [-0.203, -0.007]. See Figure 1 for path estimates.

Identity relevance. As expected, racial identity relevance was not a significant moderator of the direct effect of participant race on perceptions of isolated racism, $b=0.01, S E=0.22, p>$ .250 , CI $[-0.421,0.430]$. However, and as expected, racial identity relevance was a significant moderator of the direct effect of participant race on perceptions of systemic racism, $b$ $=-0.41, S E=0.20, p=.040$, CI $[-0.798,-0.019]$. Probing this same, moderated direct effect using the Johnson-Neyman technique (Hayes, 2013) with PROCESS Model 1 template reveals, consistent with hypotheses, that Black participants perceive significantly more systemic racism than White participants at or above the 5.43 level of racial identity relevance, with $69 \%$ of participants' average identity relevance response falling above this point and within the region of significance (see Supplemental Figure S1). The size of this Black-White gap in systemic racism perceptions continues to grow as racial identity increases. Below this point, White and Black participants' perceptions of systemic racism do not differ significantly. Additional interaction probing using regression centering with PROCESS Model 5 (see Hayes, 2013) reveals that racial identity relevance unexpectedly did not significantly predict systemic racism perceptions for Black participants, $b=0.19, S E=0.17, p>.250$, CI $[-0.150,0.539]$. This relationship was, however, in the predicted direction, with greater racial identity relevance being associated with greater systemic racism perceptions. As predicted, the opposite pattern emerged for White participants, with greater racial identity relevance being significantly associated with lower systemic racism perceptions, $b=-0.21, S E=0.10$, $p=.026$, CI $[-0.403,-0.025]$.

\section{Discussion}

Study 1 strengthens evidence for ignorance technologies: Whites (vs. Blacks) denied systemic racism more and stronger positive racial identity predicted Whites' systemic racism denial. Whites (vs. Blacks) also displayed less critical historical knowledge, which explained systemic racism denial. Participant race neither directly nor indirectly (via historical knowledge) affected isolated racism perceptions, mirroring Nelson and colleagues' smaller group effect size for isolated versus systemic racism and their contention that Whites more readily acknowledge isolated (vs. systemic) racism.

The present study's Black-White isolated racism gap is, however, not only smaller, it is nonexistent-a pattern consistent with our argument that "racially diverse and valuing diversity" institutional culture may minimize racism perception group differences. For example, perhaps this institution's White students feel free to acknowledge isolated racism because the broader context has solidified a positive, egalitarian community member image. Simultaneously, this institution's Black students may be less attuned to racism examples- $\mathrm{HBCU}$ cultural contexts may more effectively raise 
critical consciousness than other MSIs (Dickens \& Taylor, 2016; Lewis \& Lee, 2009). Future work should examine group differences across HBCUs, other MSIs, and PWIs.

Interestingly, Study 1's statistical model shows that critical historical knowledge's mediating role remains when accounting for motivated, identity-relevant systemic racism denial. Exploratory analyses also show that identity relevance does not moderate the racial group indirect effect on systemic racism (Hayes, 2015). These analyses suggest that motivated, identity-relevant systemic racism denial is separable from historical ignorance. Contrastingly, other work shows that group esteem concerns can reduce the likelihood of seeking historical facts that negatively depict one's group (Kurtiş, Adams, \& Yellow Bird, 2010; Sahdra \& Ross, 2007). The present institution's diversity-related course requirements could be mitigating this established relationship.

Critically, and despite the isolated racism null effect, Study 1 Whites demonstrated less critical historical knowledge and relative difficulty acknowledging systemic racism. Study 2 begins addressing this problem by attempting to boost critical historical knowledge in a way that targets understandings of systemic racism. We also expect this intervention to provide causal evidence for the Marley hypothesis, further solidifying evidence that lacking historical knowledge leads to denying racism (Salter \& Adams, 2016).

\section{Study 2}

\section{Learning History, Acknowledging Racism}

Study 2 introduces a short critical history intervention to increase racism perceptions among Whites. It mentions isolated racism but targets systemic racism because Study 1 group differences were larger for-and historical knowledge only mediated - systemic racism. The intervention does so via an engaging historical narrative of place-focused systemic inequality. Participants listened to a control clip or historian Richard Rothstein discuss the federal government's role in creating Black ghettos, and how racialized space still perpetuates structural inequality today (cf. Bonam, Bergsieker, \& Eberhardt, 2016; Bonam, Taylor, \& Yantis, 2017; Lipsitz, 2011; Rothstein, 2015). We therefore extend evidence of the link between critical history and racism perceptions, by newly examining this key form of place-focused critical history. We expect people to learn new information about place-focused critical history from the intervention, which should in turn heighten their personal belief that Black ghettos are products of long-standing, systemic problems. We expect this shift in perspective to ultimately boost acknowledgment of other present-day systemic racism manifestations. Finally, we expect greater racial identity relevance to temper the intervention's effectiveness.

\section{Method}

\section{Participants}

Initially, 387 White adults took an online survey through MTurk. Participants indicating that they did not carefully listen to the entire audio clip were excluded, final $N=369$ (127 men, 241 women, 1 Other/unspecified; $M_{\text {age }}=38.34, S D=13.19$, $\left.M d n_{\text {age }}=34\right)$. Target sample size $(N=364)$ was set for $80 \%$ power given a pilot study's effect size (see Supplemental Material). Based on piloting, we aimed to oversample by $5 \%$ to account for participants not listening to the entire audio clip. Analyses began after fielding ended.

\section{Procedure}

Participants were randomly assigned to listen to an excerpt of one of the two episodes of National Public Radio's Fresh Air. The control and treatment conditions covered pig intelligence $(n=186)$ and U.S. ghettos $(n=183)$, respectively. All participants wrote about their initial reactions to the excerpt; provided their perceptions of isolated ( 5 items, $\alpha=.84$ ) and systemic ( 9 items, $\alpha=.91$ ) racism; self-reported the extent to which the audio clip helped them learn something new about the history of U.S. racism ( 2 items, $1-5$ scale, $\alpha=.94$ ); indicated the extent to which they personally believe the government intentionally created Black ghettos via housing policy ${ }^{4}$ ( 3 items, $\alpha=.82$ ); and completed a place-based critical historical knowledge test (4 items covering treatment clip content, reported as number correct), follow-up engagement items, racial identity relevance (4 items from Study 1, $\alpha=.82$ ), and demographics (all scales 1-7 unless otherwise noted, see Supplemental Material for verbatim items). ${ }^{5}$

\section{Fresh Air Audio Clips}

The treatment was an edited clip (11 min, $22 \mathrm{~s}$ ) from an interview with historian Richard Rothstein discussing his research on the role of racially discriminatory housing policy in the creation of Black U.S. ghettos (Gross, 2015b). The control was an edited clip (10 min, $12 \mathrm{~s}$ ) from an interview with journalist Barry Estabrook discussing his research on pig intelligence (Gross, 2015a). (see Supplemental Material for the full audio clips, instructions letting participants know that they must listen to audio in order to participate, a research team "views disclaimer" intended to reduce demand effects, and additional instructions intended to boost audio clip engagement.)

\section{Results}

Attention checks and self-reports indicate equal engagement with both audio clips, which remains when controlling for racial identity relevance (see Supplemental Material). As expected, independent samples $t$ tests reveal that treatment (vs. control) participants performed better on the test of place-based critical historical knowledge, self-reported learning more about the history of racism in the United States, reported greater personal belief that the government intentionally created Black ghettos via housing policy, and did not differ in racial identity relevance (see Table 3 ).

A mixed-model ANOVA revealed an interaction between condition (between-subjects: control, treatment) and racism type 
Table 3. Between-Group Differences in Means for Key Study 2 Variables.

\begin{tabular}{|c|c|c|c|}
\hline Measure & $\begin{array}{l}\text { Treatment } \\
\text { (Housing) }\end{array}$ & $\begin{array}{l}\text { Control } \\
\text { (Pigs) }\end{array}$ & $t(d f)$ \\
\hline POR (isolated incidents) & $4.86(\mathrm{I} .44)$ & $4.73(1.53)$ & $0.84(367)$ \\
\hline $\begin{array}{l}\text { POR (systemic } \\
\text { manifestations) }\end{array}$ & $4.07(1.60)$ & $3.65(1.49)$ & $2.60 * *(367)$ \\
\hline $\begin{array}{l}\text { Historical knowledge: } \\
\text { self-report }\end{array}$ & $4.05(1.00)$ & $1.33(0.86)$ & $28.05 * * *(367)$ \\
\hline Historical knowledge: test & $3.08(0.87)$ & $1.77(0.98)$ & $13.53^{* * *}(367)$ \\
\hline Black ghetto beliefs & $5.84(\mathrm{I} .26)$ & $4.00(1.43)$ & $13.08 * * *(366)$ \\
\hline Identity relevance & $5.21(1.18)$ & $5.33(1.21)$ & $-0.98(367)$ \\
\hline
\end{tabular}

Note. Standard deviations are in parentheses. POR $=$ perception of racism. ${ }^{*} p<.05 .{ }^{* *} p<.01 .{ }^{* * *} p<.001$.

Table 4. Correlations ( $r$ ) Between Dependent Measures in Study 2.

\begin{tabular}{|c|c|c|c|c|c|}
\hline Measure & 2 & 3 & 4 & 5 & 6 \\
\hline $\begin{array}{l}\text { I. Historical knowledge: } \\
\text { self-report }\end{array}$ & $.50 * * *$ & $.61^{* * *}$ & $-.32 * * *$ & $-.15^{* *}$ & -.08 \\
\hline $\begin{array}{l}\text { 2. Historical knowledge: } \\
\text { test }\end{array}$ & & $.46 * * *$ & $.15^{* *}$ & $.21 * * *$ & -.01 \\
\hline 3. Black ghetto beliefs & & & $-.4 \mid * * *$ & $-.48 * * *$ & $-.19 * * *$ \\
\hline $\begin{array}{l}\text { 4. POR: isolated } \\
\text { incidents }\end{array}$ & & & & $.64 * * *$ & $-.17^{* * *}$ \\
\hline $\begin{array}{l}\text { 5. POR: systemic } \\
\text { manifestations }\end{array}$ & & & & & $-.38 * * *$ \\
\hline 6. Identity relevance & & & & & \\
\hline
\end{tabular}

Note. POR $=$ perception of racism.

$* * p<.01 .{ }^{* * *} p<.001$.

(within-subjects: isolated, systemic), $F(1,367)=4.68, p=.03, \eta_{\mathrm{p}}^{2}$ $=.01$. The overall tendency to report greater isolated versus systemic racism perceptions, $F(1,367)=193.33, p<.001, \eta_{\mathrm{p}}^{2}=$ .35 , was smaller for treatment, $F(1,367)=68.38, p<.001, \eta_{\mathrm{p}}^{2}$ $=.16$, versus control participants, $F(1,367)=130.13, p<.001$, $\eta_{\mathrm{p}}^{2}=.26$. Additionally, the tendency for treatment versus control participants to report greater racism perceptions overall, $F(1$, $367)=3.68, p=.056, \eta_{\mathrm{p}}^{2}=.01$, was present for systemic racism, $F(1,367)=6.77, p<.01, \eta_{\mathrm{p}}^{2}=.02$, but not isolated racism, $F<1$ (see Table 4 for bivariate correlations between all measures).

\section{Testing the Marley Hypothesis and Role of Identity Relevance Simultaneously}

We conducted serial mediated moderation regression analyses using Study 1's procedures with a custom PROCESS version 3 model, to test the Marley hypothesis and role of racial identity relevance. We test (1) whether condition has an indirect effect on perceptions of racism through historical knowledge gained and, in turn, personal beliefs about Black ghettos (controlling for racial identity relevance) and (2) whether racial identity relevance moderates the direct treatment effect (i.e., controlling for historical knowledge gained and beliefs about Black ghettos) on racism perceptions (see Figure 2 for path estimates). ${ }^{6}$

Marley hypothesis. Unexpectedly, the condition $\rightarrow$ historical knowledge $\rightarrow$ Black ghetto beliefs $\rightarrow$ isolated racism perceptions indirect path was significant, $b=0.57, S E=0.14$, CI [0.328, $0.864]$. As expected, the condition $\rightarrow$ historical knowledge $\rightarrow$ Black ghetto beliefs $\rightarrow$ systemic racism perceptions indirect path was also significant, $b=0.56, S E=0.13$, CI [0.334, 0.839].

Identity relevance. As expected, racial identity relevance did not moderate the direct treatment effect on isolated racism perceptions, $b=-0.04, S E=0.11, p>.250$, CI [-0.266, 0.188]. ${ }^{7}$ Also as expected, racial identity did indeed moderate the direct treatment effect on systemic racism perceptions, $b=-0.27$, $S E=0.11, p=.014$, CI [ $-0.488,-0.055]$. Specifically, the direct effect is statistically negative and smallest in magnitude at one $S D$ below this sample's racial identity mean, $b=-0.77$, $S E=0.26, p<.01$, CI $[-1.277,-0.255]$. Its magnitude then increases both at the sample mean, $b=-1.09, S E=0.23$, $p<.001$, CI $[-1.549,-0.631]$, and again at one $S D$ above the mean, $b=-1.41, S E=0.28, p<.001$, CI [-1.956, -0.872]. Thus, consistent with hypotheses, the treatment becomes less likely to increase systemic racism perceptions as racial identity increases (see Supplemental Figure S2).

Note that, unexpectedly (but not inconsistent with predictions), the direct treatment effect on both isolated and systemic racism perceptions is significant and statistically negative for the sample overall. ${ }^{8}$ When accounting for variation in both isolated and systemic racism perceptions that is predicted by the statistically positive indirect treatment effect through critical historical knowledge and Black ghetto beliefs, the remaining variation in racism perceptions that is predicted by the treatment alone (i.e., the direct treatment effect) is such that receiving the treatment (vs. control) condition actually predicted a decrease in both forms of racism perceptions. As the racial identity moderation analyses demonstrate, the magnitude of this decrease is predicted by levels of identification: As positive racial identity increases, the negative direct effect of the treatment on systemic racism perceptions increases. Note that this direct effect is also in the opposite direction of the total treatment effect (i.e., the sum of the direct and indirect treatment effects).

\section{Discussion}

Study 2 provides experimental support for the Marley hypothesis by demonstrating that exposure to critical historical information, via a National Public Radio program, can help White Americans' acknowledge present-day racism. This finding highlights the important disruption of ignorance technologies that critical educational programming can provide. Specifically, participants learned new information about racism in the past (housing policy), which shifted their personal beliefs about the target of that particular form of racism (Black ghettos), ultimately facilitating their acknowledgment of other present-day systemic racism manifestations. Notably, this intervention applies the relationship 


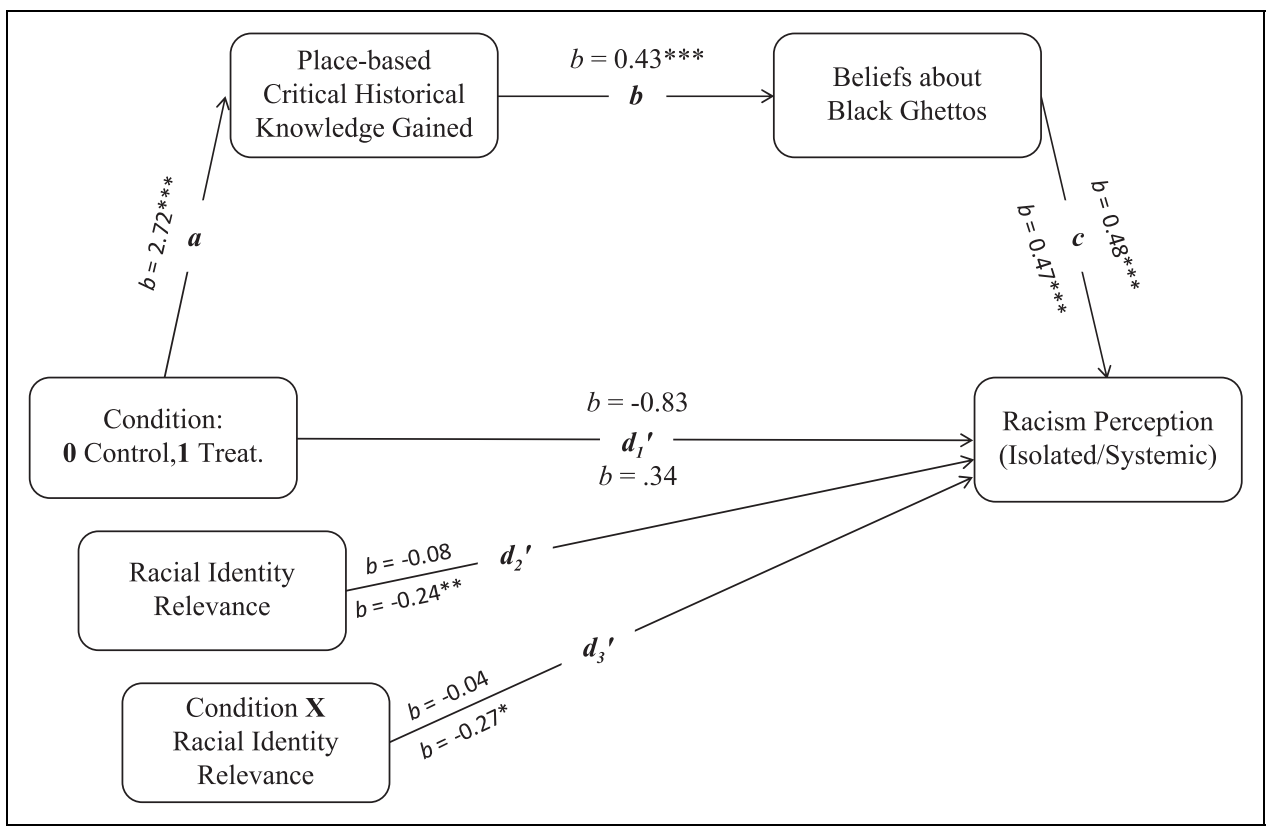

Figure 2. A statistical depiction of Study 2's model, simultaneously testing the Marley and identity relevance hypotheses. Unstandardized path estimates predicting isolated and systemic racism perceptions are above and below the lines, respectively. (Treat. = treatment; higher beliefs about black ghettos indicate greater personal belief that the government intentionally used housing policy to create Black ghettos; higher racial identity relevance indicates a more positive racial identity.). ${ }^{* * *} p<.00 \mathrm{I} . *_{p}<.0 \mathrm{I}$. $*_{p}<.05$.

between critical history and racism perceptions to a new form of place-focused critical history in order to effectively target systemic racism perceptions.

Interestingly, when accounting for this indirect process involving critical historical knowledge, we found statistical evidence of a relatively weaker, but reversed direct effect where the intervention also contributes to dampened isolated and systemic racism perceptions. The intervention appears to simultaneously catalyze two opposing psychological processes. Further, this flipped direct effect on systemic racism becomes stronger as racial identity relevance increases, consistent with our hypothesis that motivation to protect group esteem would temper the intervention's effectiveness. Ongoing qualitative work provides nuanced evidence that psychological reactance produces this flipped direct effect, along with novel suggestions for managing such reactance while learning critical history (Coleman, Bonam, \& Yantis, 2018).

Future work will also examine this brief intervention's longitudinal effectiveness and factors boosting its lasting effects. To help identify these factors, we are embedding this intervention into broader social justice course curricula. Students complete a classroom-based participatory action research project encouraging peers to explore student-centered approaches for expanding the intervention.

\section{General Discussion}

Findings support the Marley and identity relevance hypotheses: In Study 1, White (vs. Black) Americans attending a racially diverse university were more likely to deny systemic racism. Knowledge of critical history and racial identity relevance independently contributed to this perceptual gap. Specifically, elevated group esteem among Whites predicted greater systemic (but not isolated) racism denial. Additionally, Whites demonstrated less critical historical knowledge, which explained why they denied systemic (but not isolated) racism more than Blacks. A Study 2 intervention facilitated Whites' acknowledgment of systemic racism, by communicating new information about place-based critical history. Racial identity was again relevant: elevated group esteem tempered the intervention's effect on systemic racism perceptions.

\section{Supporting the Epistemologies of Ignorance Framework and Ignorance Technologies}

An epistemologies of ignorance approach (Mills, 2007) frames dominant perspectives not as neutral or unremarkable, but as subjective and motivated, in ways that reproduce injustice. Our findings support this framework by providing further evidence that ignorance of race as an evolving historical process is not neutral but tied to White American ways of seeing the world. Ignorance of this history dampens contemporary racism perceptions, revealing the subjective nature of racism denial embedded within dominant White perspectives. Additionally, a positive racial identity predicts White Americans' tendency to deny the fact of present-day racism, also suggesting that this denial is a subjective perception that is motivated, at least in part, by the desire to protect a positive racial group image. Another possibility is that those White Americans with a stronger positive racial group image are also more likely to have been exposed to other forms of identity-relevant cultural knowledge that foster denial of present-day racism. This denial 
is particularly worthy of further study because believing that the problem does not exist confers the privilege of not feeling responsible for fixing it. Indeed, denying racism depresses support for anti-racist policy (Salter \& Adams, 2016).

\section{Context, Culture, and Intervention}

Demonstrating the power and pervasiveness of ignorance technologies, this denial occurred at an institution with group minimizing characteristics - a racially diverse higher educational context where "valuing diversity" narratives prevail. This evidence suggests that Nelson and colleagues' racial group differences were not solely produced by the different contexts from which Black and White participants were drawn, and that they generalize beyond Black and White people who self-select into HBCUs and PWIs, respectively. Instead, more pervasive cultural narratives - beyond these particular university contexts - likely shape racially divergent perspectives on racism, identity, and history.

Pervasive cultural narratives make the question of intervening a difficult one to answer. Our findings provide insight by showing that a brief intervention targeting systemic racism understandings can boost acknowledgment of systemic racism manifestations. The intervention conveys the critical history of how race is placed and the built environment as an intentionally racialized cultural product (Bonam et al., 2017) that perpetuates racial inequality today. Considering the important role racism perceptions likely play in advancing anti-racist action (Salter \& Adams, 2016), the present work highlights the continuing need for mainstream education about the history of today's racial inequality.

\section{Acknowledgments}

The authors would like to thank Cynthia Roebuck for manuscript preparation assistance.

\section{Declaration of Conflicting Interests}

The author(s) declared no potential conflicts of interest with respect to the research, authorship, and/or publication of this article.

\section{Funding}

The author(s) received no financial support for the research, authorship, and/or publication of this article.

\section{Notes}

1. We use "tool" in a metaphorical sense throughout this article, to highlight how the focal psychological processes carry out particular functions (as do actual tools) that reveal the subjective and culturally embedded nature of how people characterize present-day manifestations of racism.

2. Additional students participated in this study: 128 Asian Americans, 127 Latino Americans, 2 American Indians, 32 Arab Americans, 15 listed "Other," and 11 did not report their racial/ethnic background. Findings comparing these groups to the Black American participants will be a focus of secondary analyses to be reported in a subsequent manuscript.
3. We also administered the Public Regard and Centrality subscales of Collective Self-Esteem Scale (Luhtanen \& Crocker, 1992) to be reported as secondary analyses in a subsequent manuscript.

4. One control participant did not complete this measure.

5. To keep procedures consistent across conditions, all participants also self-reported the extent to which the audio clip helped them learn something new about pig intelligence; indicated the extent to which they personally believe that pigs are intelligent; and completed a pig-related knowledge test.

6. Analyses here use self-reported historical knowledge. Additionally, all conclusions remain the same when using historical knowledge test score instead.

7. More specifically, the magnitude of the direct treatment effect on isolated racism perceptions did not differ when evaluated at the sample's racial identity relevance mean, $b=-1.04, S E=0.25$, $p<.001$, CI $[-1.518,-0.553]$; at one $S D$ below it, $b=-0.99$, $S E=0.27, p<.001$, CI $[-1.526,-0.453]$; and at one $S D$ above it, $b=-1.08, S E=0.29, p<.001$, CI [-1.651, -0.512$]$.

8. We obtained this direct treatment effect on isolated racism perceptions for the sample overall $(b=-1.03, S E=0.24$, $p<.001, \mathrm{CI}[-1.510,-0.549])$ by running Process Model 6 template to test the same basic model represented in Figure 2, except the nonsignificant treatment by racial identity relevance interaction term was removed and racial identity relevance was instead entered as a covariate.

\section{Supplemental Material}

The supplemental material is available in the online version of the article.

\section{References}

Adams, G., \& Markus, H. R. (2004). Toward a conception of culture suitable for a social psychology of culture. In M. Schaller \& C. S. Crandall (Eds.), The psychological foundations of culture (pp. 335-360). Mahwah, NJ: Lawrence Erlbaum.

Adams, G., Tormala, T. T., \& O'Brien, L. T. (2006). The effect of self-affirmation on perception of racism. Journal of Experimental Social Psychology, 42, 616-626. doi:10.1016/j.jesp. 2005.11.001

Bergsieker, H. B., Shelton, J. N., \& Richeson, J. A. (2010). To be liked versus respected: Divergent goals in interracial interactions. Journal of Personality and Social Psychology, 99, 248-264. doi:10. 1037/a0018474

Bonam, C. M., Bergsieker, H. B., \& Eberhardt, J. L. (2016). Polluting Black space. Journal of Experimental Psychology: General, 145, 1561-1582. doi:10.1037/xge0000226

Bonam, C. M., Taylor, V. J., \& Yantis, C. (2017). Racialized physical space as cultural product. Social and Personality Psychology Compass, 11, 1-12. doi: 10.1111/spc3.12340

Bonilla-Silva, E. (2015). The structure of racism in color-blind, "postracial" America. American Behavioral Scientist, 59, 1358-1376. doi:10.1177/0002764215586826

Bynum, M. S., Burton, E. T., \& Best, C. (2007). Racism experiences and psychological functioning in African American college freshmen: Is racial socialization a buffer? Cultural Diversity and Ethnic Minority Psychology, 13, 64-71. doi:10.1037/1099-9809.13.1.64 
Cabrera, N. L., Watson, J. S., \& Franklin, J. D. (2016). Racial arrested development: A critical whiteness analysis of the campus ecology. Journal of College Student Development, 57, 119-134. doi:10.1353/csd.2016.0014

Charles, C. Z. (2003). The dynamics of racial residential segregation. Annual Review of Sociology, 29, 167-207. doi:10.1146/annurev. soc.29.010202.100002

Civil Rights Office. (2016). Minority serving institutions program. Retrieved September 24, 2016, from https://www.doi.gov/pmb/ eeo/doi-minority-serving-institutions-program

Coleman, Bonam, \& Yantis. (2018). "I Thought Ghettos Just Happened": White Americans' responses to learning about systemic racism. Manuscript in preparation.

Dickens, D., \& Taylor, V. J.(2016). A site of resistance: An intersectional approach to understanding black women's motivations to attend an historically black college for women. Unpublished manuscript.

Gross, T. (2015a, May 5). "Tales" of pig intelligence, factory farming and humane bacon. National Public Radio. Retrieved from http:// www.npr.org/sections/thesalt/2015/05/05/402584436/tales-of-pigintelligence-factory-farming-and-humane-bacon

Gross, T. (2015b, May 14). Historian says don't "sanitize" how our government created black ghettos. National Public Radio. Retrieved from http://www.npr.org/2015/05/14/406699264/histor ian-says-dont-sanitize-how-our-government-created-the-ghettos

Gunn, G. R., \& Wilson, A. E. (2011). Acknowledging the skeletons in our closet: The effect of group affirmation on collective guilt, collective shame, and reparatory attitudes. Personality and Social Psychology Bulletin, 37, 1474-1487. doi:10.1177/0146 167211413607

Hayes, A. F. (2013). An introduction to mediation, moderation, and conditional process analysis: A regression-based approach. New York, NY: Guilford Press.

Hayes, A. F. (2015). An index and test of linear moderated mediation. Multivariate Behavioral Research, 50, 1-22. doi:10.1080/ 00273171.2014 .962683

Institutional Research Office. (2015). The National Survey of Student Engagement Results. www.nsse.indiana.edu

Kurtiş, T., Adams, G., \& Yellow Bird, M. (2010). Generosity or genocide? Identity implications of silence in American Thanksgiving commemorations. Memory, 18, 208-224. doi:10.1080/ 09658210903176478

Lewis, M. K., \& Lee, A. K. (2009). Critical consciousness in introductory psychology: A historically black university context. Pedagogy and the Human Sciences, 1, 50-60.

Lipsitz, G. (2011). How racism takes place. Philadelphia, PA: Temple University Press.

Liu, J. H., \& Hilton, D. J. (2010). How the past weighs on the present: Social representations of history and their role in identity politics. British Journal of Social Psychology, 44, 537-556. doi:10.1348/ $014466605 \times 27162$

Lopez, G. E. (2004). Interethnic contact, curriculum, and attitudes in the first year of college. Journal of Social Issues, 60, 75-94. doi: 10.1111/j.0022-4537.2004.00100.x

Lopez, G. E., Gurin, P., \& Nagda, B. A. (1998). Education and understanding structural causes for group inequalities. Political Psychology, 19, 305-329. doi:10.2307/3792050
Luhtanen, R., \& Crocker, J. (1992). A collective self-esteem scale. Personality and Social Psychology Bulletin, 18, 302-318. doi:10. 1177/0146167292183006

Marley, R. N., \& Williams, N. G. (1983). Buffalo soldier. London, England: Island Records.

Mills, C. W. (1997). The racial contract. Ithaca, NY: Cornell University Press.

Mills, C. W., \& White, ignorance. (2007). In S. Sullivan \& N. Tuana (Eds.), Race and epistemologies of ignorance. Albany: State University of New York Press.

elson, J. C., Adams, G., \& Salter, P. S. (2013). The Marley hypothesis: Denial of racism reflects ignorance of history. Psychological Science, 24, 213-218. doi:10.1177/0956797612451466

Pew Research Center. (2016). On views of race and inequality, Blacks and Whites are worlds apart. Retrieved from http://www.pewso cialtrends.org/2016/06/27/on-views-of-race-and-inequalityblacks-and-whites-are-worlds-apart/

Rothstein, R. (2015). The making of Ferguson (pp. 1-41). Economic Policy Institute. Retrieved from epi.org/publication/making-ferguson

Sahdra, B., \& Ross, M. (2007). Group identification and historical memory. Personality and Social Psychology Bulletin, 33, 384-395. doi:10.1177/0146167206296103

Salter, P. S., \& Adams, G. (2016). On the intentionality of cultural products: Representations of black history as psychological affordances. Frontiers in Psychology, 7, 343-321. doi:10.3389/fpsyg.2016.01166

Smith-Barrow, D. (2015, May 5). See the most diverse national universities. Retrieved September 24, 2016, from http://www. usnews.com/education/best-colleges/slideshows/see-the-mostdiverse-national-universities

Sommers, S. R., \& Norton, M. I. (2006). Lay theories about White racists: What constitutes racism (and what doesn't). Group Processes \& Intergroup Relations, 9, 117-138. doi:10.1177/ 1368430206059881

Unzueta, M. M., \& Lowery, B. S. (2008). Defining racism safely: The role of self-image maintenance on white Americans' conceptions of racism. Journal of Experimental Social Psychology, 44, 1491-1497. doi:10.1016/j.jesp.2008.07.011

Van Camp, D., Barden, J., Sloan, L. R., \& Clarke, R. P. (2009). Choosing an HBCU: An opportunity to pursue racial self-development. The Journal of Negro Education, 78, 457-468. doi:10.2307/25676099

Wise, T. (2006, April 23). What kind of card is race? Retrieved December 10, 2016, from counterpunch.org/2006/04/24/whatkind-of-card-is-race/

\section{Author Biographies}

Courtney M. Bonam is an assistant professor at the University of Illinois at Chicago.

Vinod Nair Das is a doctoral student at the University of Illinois at Chicago.

Brett R. Coleman is an assistant professor at Western Washington University.

Phia Salter is an assistant professor at Texas A\&M University.

Handling Editor: Elizabeth Paluck 